\title{
As relações funcionais e simbólicas do objeto no design
}

Functional and symbolic relations of the object in design

SILVA, Conrado Renan da

Universidade Estadual Paulista - UNESP I conradorenansilva@gmail.com

SADER, Ana Paula Cabral

Centro Universitário Toledo I anapaulasader@terra.com.br

\begin{abstract}
Resumo
O design contribui de maneira singular na cultura material pois está presente em tudo ao nosso redor, seja nos produtos mais simples ou nos tecnológicos. A cada dia novos produtos são lançados no mercado e o problema é que nem sempre esses produtos são realmente úteis e necessários. O que se vê é um aumento exagerado do consumo e desejo de posse, uma relação que tem se tornado insustentável. As relações existentes entre função e simbolismo dentro do design já não sobrevivem isoladas, e, para que um produto seja considerado bom, a forma deve seguir uma função, mas deve também ser atrativa visualmente e despertar emoções nas pessoas. Essa relação equilibrada garante que os projetos sejam bem-sucedidos e melhor aproveitados, deste modo, o design estará contribuindo com a cultura material, atentando-se também às questões sociais e sustentáveis, fatores considerados fundamentais na atualidade.
\end{abstract}

Palavras-chave: Objeto. Forma. Função. Símbolo.

\section{Abstract}

Design contributes in a very unique way to the material culture, for it is present in everything around us - from regular products to complex technology solutions. Every day new products are launched in the market and the problem is that they are not always really useful and necessary. There has been an exaggerated increase in consumption and desire for possession, a relationship that has become unsustainable. The relationship between function and symbolism in design is closer than ever: a product is considered "good" if "the form follows the function", but it should also be visually attractive and arouse emotions. This balanced approach ensures that design projects are more successful and useful. Thus, design contributes to the material culture while shedding light to social and sustainability issues - considered fundamental aspects today.

Keywords: Object. Shape. Function. Symbol. 


\section{INTRODUC̣ÃO}

O design tem sido uma ferramenta fundamental para a formação e desenvolvimento da cultura material. "Entende-se a cultura material como o universo de coisas- objetos/artefatos - que permeiam a vida social" (REIS, 2005). Essa representação através dos objetos ou produtos devem atender às necessidades de seus usuários a partir de seus aspectos funcionais e também simbólicos, refletindo a sociedade em seu aspecto cultural.

Para Cardoso (2013, p. 111), "as aparências dos objetos sempre são carregadas de significados, isso quer dizer que todo artefato material é comunicação, informação e signo, ou seja, todo artefato material possui também uma dimensão imaterial de informação." Sendo assim, todo objeto, produto ou artefato é um signo cultural pois faz parte de um contexto, deixando o papel do designer ainda mais carregado de responsabilidade.

Assim, percebe-se que o produto assume basicamente dois papéis: o da usabilidade, que aborda aspectos funcionais, atendendo a necessidades e seguindo uma função; e o emocional, que busca as questões simbólicas, de significados e experiências que o produto possa ter para o usuário.

Segundo Bonsiepe (2011, p. 60), "o designer deveria se preocupar com esses aspectos do design emocional em vez de lidar com coisas supostamente banais como o uso, praticidade e detalhes técnicos." O autor, ao fazer essa colocação utilizando o termo "supostamente banais", no que diz respeito aos aspectos mais técnicos, chama a atenção para que o designer atente-se ao desenvolvimento de um produto a partir das questões emocionais e não apenas das questões técnicas.

O design tem esse papel de despertar o simbolismo, o lado emocional das pessoas, contribuindo de maneira singular no desenvolvimento da cultura material, influenciando nas definições da identidade cultural de uma sociedade. "Por meio do design, atribui-se significados aos artefatos, que ficam associados a conceitos abstratos como estilo, status, identidade" (CARDOSO, 2013, p. 113).

Percebe-se então que o design não é somente "a forma que segue a função" como se ensinava na Bauhaus, embora seja uma frase que possui uma carga muito significativa para o design. Com o passar dos anos e o advento das novas tecnologias, foi necessário que os designers, para conseguir atender às necessidades das pessoas, começassem então a abordar outros aspectos que vão além da forma e da função. O design tem entrando no campo do simbolismo, da emoção e das significações que trabalham aspectos sociais e culturais. Por exemplo, para se inserir em determinados grupos sociais, algumas pessoas desejam adquirir produtos não somente pela necessidade, mas sim pelo status e posicionamento social que o produto pode proporcionar. Como 
afirma Cardoso (2013, p. 110), "as aparências características dos objetos nos remetem a vivências, hábitos e até pessoas que associamos ao contexto em que estamos acostumados a deparar com eles."

\title{
2 UMA BREVE CONCEITUAC̣ÃO ACERCA DA SEMIÓTICA
}

A questão simbólica é algo que deve ser estudado no design, pois trata da representação das coisas, o uso de signos, símbolos e seus significados "a significação é um processo que associa um objeto, um ser, uma noção ou um acontecimento a um signo capaz de os evocar" (GUIRAUD, 1980, p. 15).

Os signos servem para representar determinados objetos, mas não sendo o objeto propriamente em si, é uma imagem associada a algo ou alguma coisa, "o signo é [...] um estímulo, cuja ação sobre o organismo provoca a imagem memorial de um outro estímulo; a nuvem evoca a imagem da chuva, a palavra evoca a imagem da coisa" (GUIRAUD, 1980, p. 15).

\begin{abstract}
Todo signo é um estímulo associado, existem dois grandes tipos de associações significantes, o primeiro é a dos signos naturais que são baseados em relações existentes na natureza, como o exemplo da nuvem dado acima, e segunda a dos signos artificiais que podem ser produzidos pelo homem (ou animais) e que é subdividido em dois grupos, um serve para representar o real com caracteres naturais da realidade através de desenhos, gravações, fotografias e o outro para possibilitar a comunicação com o outro que são os signos convencionais como, placas de sinalização (GUIRAUD, 1980, p. 17).
\end{abstract}

Para Peirce (1999, p. 51), "os signos são divisíveis conforme três tricotomias, a primeira, conforme o signo em si mesmo for uma mera qualidade, [...] a segunda, conforme a relação do signo para com seu objeto [...] a terceira, conforme seu interpretante representá-lo [...]." Essa relação que é apresentada na segunda tricotomia dos signos por Peirce, faz uma associação do objeto com um interpretante. Peirce (1999, p. 52) diz que "um signo pode ser denominado Ícone, Índice ou Símbolo." O ícone representa algo através da semelhança, como exemplo a escultura de um homem não é o homem em si, uma fotografia de uma paisagem, não é a paisagem propriamente dita "um ícone é um signo que se refere ao Objeto que denota apenas em virtude de seus caracteres próprios, caracteres que ele igualmente possui quer um tal objeto realmente exista ou não" (PEIRCE, 1999, p. 52).

O índice é uma indicação de algo não por semelhança, mas por proximidade, ele se relaciona por meio de um sujeito, por exemplo a fumaça indica fogo, a fumaça saindo de uma pizza e o cheiro exalando indica a pizza. 
Para Pierce (1999, p. 52) "um índice é um signo que se refere ao objeto que denota em virtude de ser realmente afetado por esse objeto [...] na medida em que o índice é afetado pelo objeto, tem ele necessariamente alguma qualidade em comum com o objeto" e é assim que se refere a ele.

O símbolo, por sua vez, traz um significado junto com um significante, fazendo com que ele represente algo associado mentalmente por um interpretante, como exemplo pode-se citar o logotipo das empresas que carregam traços marcantes da empresa ou produto e despertam nas pessoas o desejo de pertencimento. “Um símbolo é um signo que se refere ao objeto que denota em virtude de uma lei, normalmente uma associação de ideias gerais que opera no sentido de fazer com que o símbolo seja interpretado como se referindo aquele objeto" (PEIRCE, 1999, p. 52).

Entender as significações e os símbolos deve fazer parte do cotidiano do designer, e, quando bem explorado nos projetos, esse entendimento e interpretação são determinantes para o desenvolvimento de um produto com melhor qualidade e com uma maior aceitação pelas pessoas.

\section{SEMIÓTICA, SIGNO E SÍMBOLO NO DESIGN}

Existe uma preocupação do designer de trabalhar o lado da emoção das pessoas nos produtos, pois, "por meio da visualidade, o design é capaz de sugerir atitudes, estimular comportamentos e equacionar problemas complexos" (CARDOSO, 2013, p. 117). A questão simbólica no design estuda essa relação de funções adicionais aos produtos, indo além da forma e função. De acordo com Löbach (2001, p.104) "esta é, dentre outras, a tarefa do designer industrial, que pode aperfeiçoar o produto mediante o emprego da configuração simbólicofuncional e a estética simbólico-funcional, transformando-o em símbolo."

O design é extremamente "visual" e tem essa capacidade de transmitir às pessoas sentimentos, emoções e até mesmo causar sensações através dos produtos, o que se configura como uma relação imagética. Essa transmissão de modo visual é responsável em despertar nas pessoas desejo ou repúdio pelo produto.

Um produto, segundo Baxter (2000), pode ser considerado atrativo quando for visualmente agradável, quando for visualmente desejável, e, "juntando-se essas duas qualidades- um produto que é capaz de chamar a atenção e se torna desejável- faz com que os consumidores se sintam arrastados em direção ao produto- o significado literal do termo atrativo" (BAXTER, 2000, p. 46). Percebe-se então que o produto possui atributos importantes que influenciam diretamente no momento de decisão do consumidor, assim, é 
interessante que objetos de design possuam esse equilíbrio em sua composição e cabe ao designer entender e decodificar esse simbolismo no momento de desenvolvimento do produto.

"Ao perceber um objeto, o nosso cérebro o classifica imediatamente como atraente ou sem atrativo. Ele faz isso instintivamente, buscando na memória emoções e sentimentos ligados a outros objetos semelhantes" (BAXTER, 2000, p. 35).

Baxter (2000) discorre ainda sobre o que faz os consumidores considerarem os produtos atrativos. Primeiramente pela atração daquilo que o consumidor já conhece, que garante o sucesso comercial devido à venda de produtos seriados, em que as pessoas precisam comprá-los com uma certa regularidade, são produtos que possuem aspectos mais tradicionais e que muitas vezes são fundamentais para o dia-a-dia. A segunda maneira é pela atração semântica, que deve transmitir confiabilidade através da imagem visual, e, nesse caso o produto deve expressar o objetivo para o qual foi feito, seja pelas cores, materiais ou formas. Como terceiro modo temos a atração simbólica que vem ao encontro com do perfil do consumidor ou então para reforçar algo que o consumidor deseja afirmar perante a sociedade, por gosto, pertencimento a determinados grupos, expressão ou status. A quarta maneira é a atração intrínseca da forma visual, que contempla os aspectos da estética do produto.

\footnotetext{
Todos nós temos uma auto-imagem, baseada nos valores pessoais e sociais que possuímos. Faz parte da natureza humana, procurarmos nos cercar de objetos que reflitam a nossa auto-imagem. A casa em que vivemos, o carro que possuímos, os lugares que frequentamos e até o nosso cachorro, todos eles fazem parte de um mosaico que, juntos, constituem a nossa imagem visual que projetamos aos outros (BAXTER, 2000, p. 189).
}

Cardoso (2013, p. 107) argumenta que "o senso comum, quando se escolhe uma roupa ou um móvel ou muitos outros tipos de artefatos, é que aquele objeto deve expressar algo sobre seu proprietário". Isto remete ao modo de projetar, o que faz com que o designer precise estar atento aos aspectos que vão além da estética ou beleza. Em um mundo em que as coisas e informações estão ficando cada vez mais acessíveis, as pessoas facilmente têm acesso às tendências de moda e consumo. Com a expansão da internet as pessoas conseguem comprar produtos oriundos de qualquer lugar do mundo de modo muito rápido e fácil, o que incorre também no aumento exacerbado do consumo, muitas vezes desnecessários. Como diz Sudjic (2010, p. 5) "nunca possuímos tantas coisas como hoje, mesmo que as utilizemos cada vez menos. As casas em que passamos tão pouco tempo são repletas de objetos." 
Esse consumo desenfreado de coisas leva-nos a uma preocupação global: o aumento de produtos banais que não se preocupam com questões sociais, de sustentabilidade, produtos ruins que estão no mercado somente para satisfazer o desejo da compra e que muitas vezes acabam se tornando inúteis no dia a dia das pessoas. Isso remete ao "mau design", termo utilizado na década de 1970. Na Inglaterra, no século XIX acontecia o movimento de reforma do design, já na Alemanha no século XX em 1907 iniciava o movimento "Deutscher Werkbund" que era uma associação formada por um grupo de arquitetos, designers e empresários, eram feitas exposições arquitetônicas e de produtos, mostrando novos materiais e conceitos de habitação, eles buscavam melhores condições de vida e melhor qualidade dos produtos industriais, dentre os expositores estavam Peter Behrens, Walter Gropius e Mies Van der Rohe que foram alguns nomes que marcaram a história do design e da arquitetura. "As pessoas acreditavam que o mau design não era somente um desperdício de trabalho e materiais, mas também corrompia a moral pública e era um sinal de degenerescência cultural" (FORTY, 2007, p. 7).

\section{O BOM DESIGN}

O que o design deveria ter, então, para ser considerado bom?

O design para ser considerado bom, deve atender alguns requisitos. Design não é somente a estética ou beleza das coisas como é visto comumente. O bom design precisa ter planejamento, pesquisa, atender necessidades e solucionar problemas. Como afirma Baxter (2000, p. 21) “O designer de produtos bem-sucedido é aquele que consegue pensar com a mente do consumidor: ele consegue interpretar necessidades, sonhos, desejos, valores e expectativas do consumidor."

Löbach (2001) considera que o design é considerado bom quando atende a três funções básicas: a Função Prática, a Função Estética e a Função Simbólica, conforme demonstra a figura a seguir.

Figura 1 - Funções de um produto.

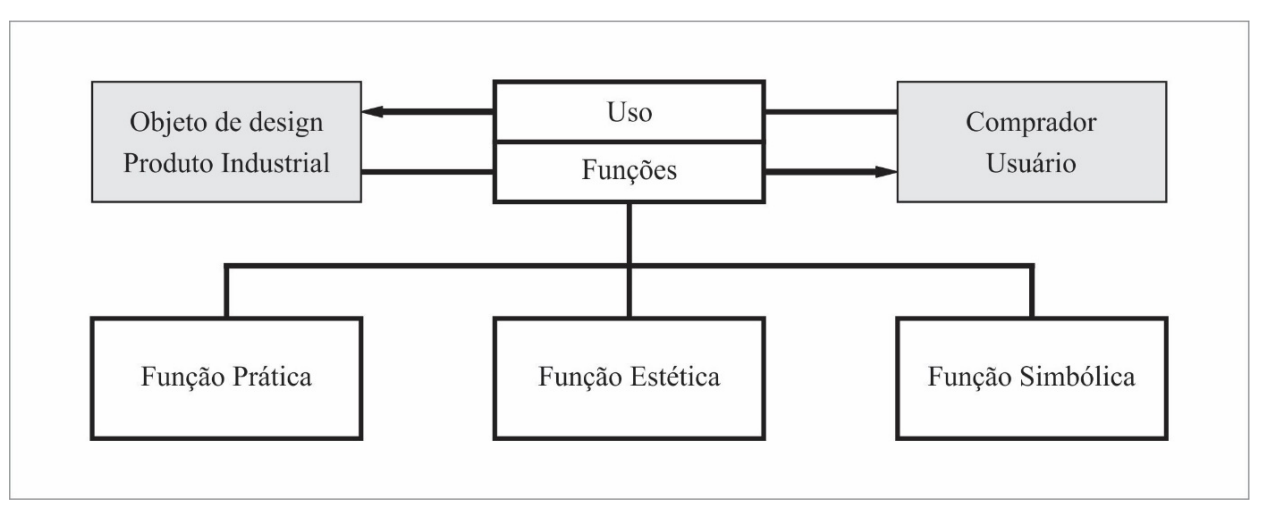

Fonte: Löbach (2001, p. 55). 
Não que o bom design fique limitado a essas três funções, mas elas podem ser fundamentais em um produto para que ele possa ser considerado bom, configurando uma relação de equilíbrio. Essa relação também deve ser analisada de acordo com o tipo de produto a ser desenvolvido pois existem produtos que necessitarão, no ato de projetar, de um olhar mais funcional e prático, como é o caso de produtos mais técnicos. "No projeto de uma engrenagem, as funções práticas estão em primeiro plano de interesse" (LÖBACH, 2001, p. 54). Em outros projetos é necessário considerar as funções estéticas e/ou simbólicas numa maior proporção, como é o caso de projetos de design de interiores em que se trabalha com o olhar, a beleza do ambiente, sendo preciso atrair a atenção do usuário e despertar nele emoções, não deixando de lado as funções práticas e funcionais, essenciais para que o projeto seja considerado bom.

"Os aspectos essenciais das relações dos usuários com os produtos industriais são as funções dos produtos, as quais se tornam perceptíveis no processo de uso e possibilitam a satisfação de certas necessidades" (LÖBACH, 2001, p. 54). As funções práticas são aquelas que atuam diretamente com o usuário e que estão relacionadas às questões de saúde e bem-estar, uma relação fisiológica. As funções estéticas se relacionam com as questões de percepções sensoriais do usuário e a simbólica remete às vivências do usuário e lembranças passadas que atribuem algum significado ao produto.

Ao analisar uma cadeira como um objeto de design, por exemplo, a sua função prática deve ser a de atender a necessidade fisiológica do seu usuário, que é sentar confortavelmente, e ela deverá preencher alguns requisitos considerados essenciais para o seu bom funcionamento, como ergonomia, resistência dos materiais utilizados, dimensionamento e conforto. Esse mesmo projeto de cadeira, quando trabalhado no campo da estética, deverá atentar para a relação com o usuário no campo sensorial através das cores, formas e texturas, como o usuário irá perceber e sentir-se atraído por ela, despertando o desejo da compra. Já a função simbólica vai ao encontro com as experiências vividas pelo indivíduo. "A função simbólica dos produtos é determinada por todos os aspectos espirituais, psíquicos e sociais de uso" (LÖBACH, 2001, p. 64), despertando emoções e atraindo o usuário pelo significado que pode the proporcionar, seja pela marca, desejo, status, cultura, dentre outros.

Todo produto industrial tem uma aparência sensorialmente perceptível, determinada por elementos de configuração, forma, cor, superfície etc. Possui também uma função estética que definimos como aspecto psicológico da percepção sensorial durante o uso. A esta função estética pode-se juntar a função prática, a função simbólica ou ambas. Sempre porém uma das funções terá prevalência sobre as outras (LÖBACH, 2001, p. 67). 
A imagem abaixo demonstra essa relação de predominâncias de funções. A predominância de uma determinada função afeta diretamente na forma do produto e no que ele representa para a sociedade de modo cultural, usual e simbólico.

Figura 2 - Predominâncias das funções do produto.

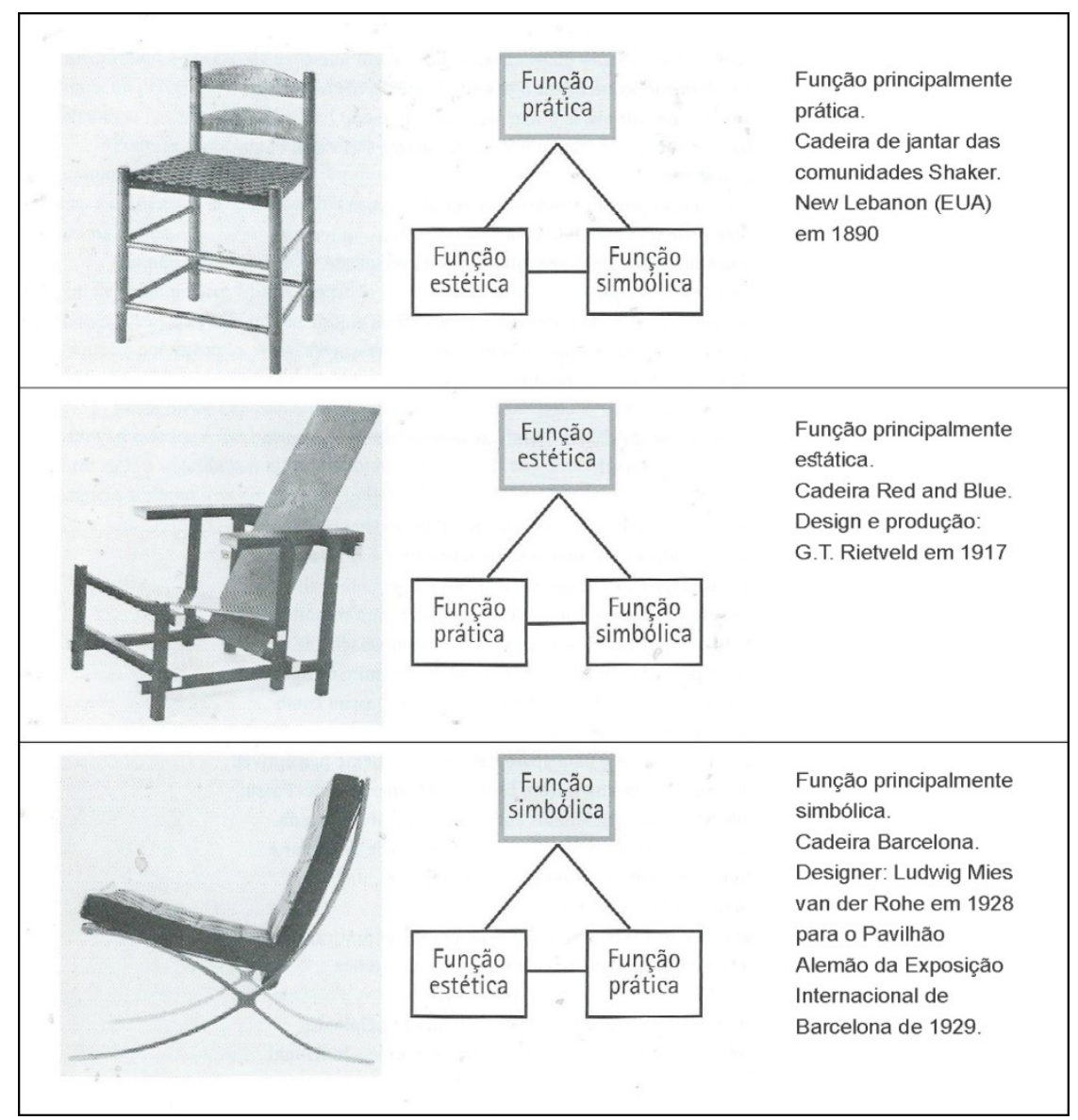

Fonte: Löbach (2001, p. 68).

Ao fazer uma análise nas três figuras, pode-se perceber a questão da predominância das funções e como isso pode afetar no resultado final de um produto. A cadeira de jantar das comunidades Shaker possui uma configuração prático-funcional, "apresenta uma aparência de unidade ótima para desempenho satisfatório de seu uso prático, com uso econômico de materiais e um processo de fabricação de custo mínimo" (LÖBACH, 2001, p.69). Na segunda figura temos a cadeira "Red and Blue" de Rietveld, exagerada em sua forma, com linhas "duras" priorizando a forma visual como um objeto de arte e que teve grande importância no ensino na Bauhaus. Em seguida temos a cadeira Barcelona, de Mies van der Rohe, de 1928. "A aparência visual da cadeira é determinada pela conjunção elegante da estrutura de aço polido e o estofamento em couro. É adequada especialmente para ser usada com finalidade de representação social" (LÖBACH, 2001, p. 70). É uma peça que possui uma carga simbólica muito forte, "é um verdadeiro símbolo de status e tem primordialmente funções simbólicas" (LÖBACH, 2001, p. 70). 


\section{OBJETOS DE DESIGN}

Basicamente, tudo o que se vê, é ou foi projetado por alguém, seja um produto, um serviço, um logotipo, o interior de uma residência, dentre outros. Tudo em algum momento foi projetado, houve algum tempo de estudo e pesquisa por algum profissional capacitado. Na prática deveria ser assim, mas nem sempre é o que se vê no mercado. É comum encontrar projetos mal executados e com erros de planejamento, que podem ocorrer por diversos fatores como despreparo do profissional ou a mão de obra desqualificada.

São diversos os fatores que influenciam no desenvolvimento de um projeto. "Existem fatores sociais, culturais e comerciais, que também influenciam. Em alguns casos, esses fatores são tão fortes, que suplantam os fatores perceptuais" (BAXTER, 2000, p. 42). Acultura tem um papel significativo no ato de projetar, por isso é possível ver projetos aparentemente iguais em lugares diferentes, mas com leituras totalmente distintas. Ao analisarmos uma poltrona como um objeto de design ou quando se solicita uma poltrona que represente a identidade de um país, ao analisar os traços culturais desse país, como símbolos, cores, estações, história, pode-se obter conteúdos riquíssimos para auxiliar no desenvolvimento dela. A cultura do Brasil possui aspectos fortes e marcantes que poderiam ser facilmente representados em um produto, como a diversidade cultural, as cores vibrantes, alegria, a beleza, o clima. O designer Sérgio Rodrigues teve a oportunidade de desenvolver uma poltrona que carregasse os traços característicos do Brasil, e que se tornou um grande ícone do design.

Figura 3 - Poltrona Mole.



Fonte: Casa Vogue (2011). 
Essa poltrona, nada mais é que um resultado de uma ótima decodificação simbólica que deve estar presente nos projetos de design. Sérgio Rodrigues, ao desenhá-la, tinha a intensão de transmitir através dela o "jeito brasileiro de sentar". Quando foi feita não teve muita aceitação, porque era oposta ao padrão das poltronas da época, mas posteriormente se tornou uma referência do design brasileiro.

O princípio de sugerir atitudes pela forma é antigo e bem mais universal do que se imagina. Quando o designer Sérgio Rodrigues projetou sua célebre Poltrona Mole, em 1957, ele atendia a uma encomenda do fotógrafo Otto Stupakoff que pediu um sofá esparramado, como se fosse de sultão. A partir da realização subsequente desse móvel, passouse a constituir todo um discurso sobre a relação entre sua forma e um suposto jeito brasileiro de sentar: largado, refestelado, folgadão. A poltrona ganhou mundo, tornandose um clássico do design e legítimo representante de uma concepção peculiar de cultura brasileira, sendo elevada por alguns comentaristas à condição de precursora da bossa nova e símbolo da modernidade nacional (CARDOSO, 2013, p. 118).

Os projetos de design se tornam bem mais interessantes quando possuem em sua essência essa característica simbólica e emocional, sem deixar de lado as questões técnicas de forma e função. O produto deve emocionar, atrair o consumidor através da percepção do olhar e, ao mesmo tempo, atender aos requisitos considerados básicos para seu funcionamento.

\section{USO E CONSUMO}

Uma importante questão a ser considerada é até que ponto as indústrias e designers tem se preocupado em produzir objetos que sejam realmente necessários para as pessoas, e se o que tem sido produzido tem servido realmente para uso. Com a constância no aumento do consumo e a obsolescência programada dos produtos, aumenta a necessidade de o designer preocupar-se com questões sociais, culturais e relativas à sustentabilidade. $\mathrm{O}$ problema é que nem sempre as indústrias, e até mesmo os designers, estão preocupados com isso.

Considerando as condições atuais de nosso planeta e a natureza catastrófica das transformações em andamento, podemos nos perguntar: qual foi o papel efetivo dos designers até agora? Infelizmente a resposta é clara demais. Falando em termos gerais, os designers têm sido, e ainda são "parte do problema". Todavia, pensamos que este 
não seja um destino inevitável. Designers podem e devem ter outro papel, tornando-se, portanto, "parte da solução". (MANZINI, 2008, p. 15).

Para se tornar parte da solução o designer deve se posicionar de forma diferente. Pensar em produzir objetos que atendam às necessidades das pessoas através dos aspectos funcionais, que possuam um simbolismo, sejam duráveis e atendam aos pilares da sustentabilidade: social, ambiental e econômico. Essa seria a configuração ideal para os produtos, mas o que se vê é uma realidade oposta a essas condições. “Desde muito, reis e nobres investiam grandes fortunas em construir e ornar seus palácios, fazendo uso da arquitetura e da arte como formas de ostentar o seu poder e de manifestar a sua glória" (CARDOSO, 2008, p.63). As pessoas desejam, através dos produtos, suprir outras necessidades pessoais e sociais, como status, fama, beleza e a mídia tem sido um dos propagadores disso.

\begin{abstract}
A indústria da moda é organizada de forma implacavelmente eficiente para impor pequenas diferenças todos os anos. A tendência é imposta pelos desfiles anuais dos "grandes nomes" do mundo da moda. Eles mostram o que as mais atraentes modelos estão usando no ano, reforçado pela imagem de pessoas influentes na sociedade e pelos ídolos de cinema, TV e esportes. As tendências e cores da moda são massificadas na forma de coleções de verão, inverno ou meia-estação e chegam às lojas. A propaganda encarregase do resto, encorajando os consumidores a andar na moda. Devido a essa pressão da propaganda, uma pessoa que esteja usando o estilo do ano passado, pode ficar incomodado, por ser considerado socialmente inferior perante os colegas. Isso pode ser uma maravilha para o comércio. Roupas que poderiam durar cinco ou seis anos são considerados obsoletos artificialmente em apenas um ano, forçando a um novo consumo, baseado na tendência social do estilo. (BAXTER, 2000, p. 43).
\end{abstract}

Esse ciclo de consumo imposto pela sociedade, mídia e indústria dificilmente vai acabar, as pessoas sempre irão comprar produtos que julgam essenciais para ela e isso independe da real necessidade de obtê-los. De acordo com Sudjic (2010, p. 21) "os objetos são nossa maneira de medir a passagem de nossas vidas. São o que usamos para nos definir, para sinalizar quem somos, e o que não somos". Essa necessidade de pertencimento faz parte da natureza humana.

Contrariamente aos mais comuns cliches em termos sociais e políticos, caminhar rumo à sustentabilidade é o contrário da conservação. Em outras palavras, a preservação e a regeneração de nosso capital ambiental e social significará 
justamente romper com as tendências dominantes em termos de estilo de vida, produção e consumo, criando e experimentando novas possibilidades. Se assim não o fizermos, se não adquirirmos experiências diferentes e se formos incapazes de aprender a partir delas, então assistiremos à verdadeira conservação, que resultará na continuação dos atuais e catastróficos estilos de vida, produção e consumo. (MANZINI, 2008, p. 15).

Para que haja uma mudança nessa questão o designer é uma peça fundamental, podendo contribuir de modo significativo na cultura material local e global. "O contexto cultural de uma sociedade pode ter uma grande influência sobre os valores e crenças individuais." (BAXTER, 2000, p. 43).

\section{CONSIDERAC̣ÕES FINAIS}

O design está presente em tudo ao nosso redor, seja nos produtos mais simples ou nos tecnológicos. A contribuição do design para a cultura material é crescente pois a cada dia são lançados novos produtos no mercado, o que nem sempre significa que sejam produtos com qualidade ou com alguma utilidade. Essa produção e consumo desenfreado acabam gerando diversos problemas e é notável a presença de objetos banais, que instigam a compra, mas que acabam sendo subutilizados. Com o aumento do consumo e o desejo das pessoas de ter os produtos, essa relação acaba se tornando insustentável.

As relações existentes entre função e simbolismo dentro do design já não sobrevivem isoladas. Para que seja considerado bom é preciso estabelecer conexões, a forma deve seguir uma função, mas deve também ser atrativa visualmente e despertar emoções nas pessoas. Para isso o designer deve procurar desenvolver uma ótica crítica e, no ato de projetar, procurar entender e atender às necessidades do seu cliente. "No processo de utilização são satisfeitas as necessidades do usuário por meio das funções dos produtos" (LÖBACH, 2001, p. 67), essas necessidades são atendidas quando o designer consegue entender o usuário através da observação e análise do seu modo de vida e decodificar isso num serviço ou produto de maneira objetiva, funcional e bela.

O design deve então satisfazer necessidades, atender às funções e provocar a emoção do usuário. Dessa forma será considerado bom e garantirá o equilíbrio necessário das relações funcionais e simbólicas dos objetos. Assim teremos projetos mais humanizados, pensados para as pessoas e não somente para atender à demanda de consumo da sociedade. Essa relação equilibrada garante que os projetos sejam bem-sucedidos e melhor aproveitados, e, desse 
modo, o design estará contribuindo com a cultura material, demonstrando preocupação com questões sociais e sustentáveis, fatores de grande importância na atualidade.

\section{REFERÊNCIAS}

BAXTER, Mike. Projeto de produto: guia prático para o design de novos produtos. 2. ed. São Paulo: Blucher, 2000.

BONSIEPE, Gui. Design, cultura e sociedade. São Paulo: Blucher, 2011.

CARDOSO, Rafael. Design para um mundo complexo. São Paulo. Cosac Naify, 2013.

CARDOSO, Rafael. Uma introdução à história do Design. 3. ed. São Paulo: Blucher, 2008.

CASA VOGUE. Há 50 anos, poltrona mole se consagrava. 2011. Disponível em: http://revista.casavogue.globo.com/design/ha-50-anos-poltrona-mole-seconsagrava. Acesso em: 15 mar. 2016.

FORTY, Adrian. Objetos de desejo: design e sociedade desde 1750. São Paulo: Cosac Naify, 2007.

GUIRAUD, Pierre. A Semântica. 3. ed. Rio de Janeiro: Difel: Difusão Editorial, 1980.

LÖBACH, Bernd. Design Industrial: bases para a configuração dos produtos industriais. São Paulo: Blucher, 2001.

MANZINI, Ezio. Design para inovação social e sustentabilidade. Rio de Janeiro: E-papers, 2008. 
PEIRCE, Charles Sanders. Semiótica. 3. ed. São Paulo: Perspectiva,1999.

REIS, Alexandre Amorim dos. Materialidade do design e cultura material. Belo horizonte, MG: Centro T \& C Design, 2005. v. 1. Disponível em: http://www. tcdesign.uemg.br/en/pdf/alexandre_amorim.pdf. Acesso em: 15 mar. 2016.

SUDJIC, Deyan. A linguagem das coisas. Rio de Janeiro: Intrínseca, 2010.

Data de submissão: 2018-05-02

Data de aceite: 2018-06-27 